\title{
Development and research on community home-based care service in China
}

\author{
JIANG Xue \\ North of China Electric Power University, China, 102206 \\ 596566037@qq.com
}

Keywords: Aging Home care Community support for the elderly Service for the Aged

Abstract: With the rise of the proportion of aged population, more and more attention is drawn to the aging problems. Currently the majority of the elderly live at home. How to base on the community, integrating all kinds of community resources, to establish a care method for the elderly man's care, intervenient from family care and institutional care. Practice shows that the community home-based care services is one of the most economical, the most feasible approach to crack pension problems. Meanwhile, it's favorable to community service industry, new focal point to promote community employment and reemployment. This paper will start from the content of home-based care service, raising the problems of that at present in China. Finally, give some suggestions combined with international experience of home care service.

\section{Home-based Care Service}

Community Services. Primarily, we should clarify the concept of community service. Some scholars indicated that community is a unity of social life with strongly regional, consisting of a certain amount of residents. Territory, population, organizational structure and culture are the basic elements for social formation. Community service was defined for the first time in our country in 1987, which would call on community members to carry out mutual social services to solve social problems with the advocacy of government. Enormous elderly people reside in community, which is the major stage and living space for them. Therefore, community services for the aged is a way to pension service with the help of government, ganged enterprise, NPO (non-profit organization) and individuals, taking full advantage of community resources.

Home care. The concept of home care began in the late 1990s.It is a combination of family endowment and community care, which is different from traditional way of family support. The places for pension are where the aged or their offspring live, sustained by the elderly endowment insurance, pension, and children's financial support. Security policy for elder people, laws and regulations of state have provided a legal basis for home care.

To sum up, we make the following definition in this paper: Home care is a new type of providing for the aged, relying on the professional services provided by the government and society, assistant family care. Family is as the core and the community is as the carrier.

\section{Content of Home-based Care Service}

\section{Content and pattern.}

Contents. Community home-based care service mainly includes three aspects: the care of daily life for the aged, spiritual solace and health care services. Care service of daily life mainly include dining, haircut, laundry and other personal hygiene services, repair of household appliances and gas 
mask, pay for public service, etc. Community care mainly visiting service, such as household service, daycare, security service, etc. Community activities enrich the life of old people through holding lectures and recreational activities.

Patterns. The operation pattern of community home-based care service, one is the daily routine, for another is to adopt the way of specific management style. For example, household service can be provided by professional housekeeping service company by the mode of government purchase of service. In the process, the government and the community is responsible for the regulation and evaluation, and entertainment activities can be delivered by fixed volunteer teams.

Relations and differences between home care and old-age care institution. First, the most significant differences are living space. The aged live in their own or their children's "house" in home-based care service, not leaving the community where they live and know well. But in old-age care institutions, the aged live in nursing homes, senile apartment, etc. Besides, cost differs between the two patterns. Home care allows eligible old men to acquire the service for free and at low cost. However, various expenses need to be paid in pension institution, which is a high cost. In terms of connection, both can offer service for society and family.

Relations and differences between home-based care and family supporting. To begin with, family supporting focus on bearing the expenses by themselves or family members. Nevertheless, home-based care service puts particular emphasis on living in home but not institutions. Moreover, family member play a major role in family supporting. In contrast, home care is with the support of community service, together with governments, enterprises and nongovernmental sectors. As far as relationship, home care is a mixture of family supporting and community supporting.

\section{The Status Quo and Problems of Home Care Service in China}

Development status in quo for home-based care service. Home-based care service have developed to a degree with successful practices, for instance:

Ningbo. Government purchase is a typical representation of services for the aged in Ningbo, China: the aged who live alone and are down and out can enjoy the government purchase services. Community is responsible for domestic helpers to carry out the door-to-door service, service standard for subsidies is 2000 yuan per person per year.

Dalian. Family type almshouse in Dalian, China, sufficiently mobilize laid-off workwomen. By relevant vocational training, standard caregivers work in the old men's home, which sends the services to their home.

Shanghai. Shanghai develops a new form to supply service by vouchers. Service voucher is divided into several service evaluation levels: "mild", "moderate" and "severe". Different service levels are corresponding to services ranging from subsidies.

\section{Problems in home-based care service.}

Contradiction between supply and demand of community home care service. Community home-based care stations are largely laid aside. For one thing, the aged are reluctant to spend money, which is a conceptual problems. For another, old people haven't formed the concept to accept old-age service, home-based care service should continue to be spread.

Community home care service staves aren't professional. So far, staves engaged in pension service have insufficient knowledge, and most of them are laid-off workers, who didn't accept the vocational training provided by relevant departments. Meanwhile community mainly undertake all kinds of work (mostly administrative work) assigned by upper governments. Most of the community just provide the elderly activity places.

Propaganda is insufficient. Demands of community residents are not urgent, so that the 
home-based care service hasn't be given enough attention. Because of the deficiency of publicity, most old people even don't know what community home care is. Even the men heard of, not enjoy the service mostly. So old people's comprehending toward care institution and community home care is misunderstood.

Home care service is narrowed. First of all, the service target of home care in reality is narrowed. Any old man who has a service need should be the object, not only the man in an economic hardship, in the minority. Most elders believe that services provided by governments have nothing to do with themselves, and the function of communities is just to organize cultural and sports activities. The elderly are severely neglected.

Low level of socialization to home-based care service. Domestic grassroots community construction is lack of vigour, which not really works. Furthermore, domestic non-governmental organizations and enterprises are lack of participation, volunteers are badly in need of extension. The government should encourage private capital to enter the community home-based care service, to provide more comfortable, targeted different levels of pension services for the elderly.

\section{External Experiences}

England. In England, home care service is led by the government, Communities, families and individuals just pay less costs. This kind of community care is generally with the help of non-system way.

America. Market-oriented home care is prime in America. The government is not the body of operation, nor the service provider directly, but administrate retirement organization in an indirect way.

Japan. Care service is also called "service in the house". The aged receive service in their own home, but also accept a variety of services from outside. A service system for the elderly has been formed where governments, enterprises, non-profit organizations, and many other subjects gang.

\section{Advice and Directions to Domestic Home Care}

Strengthen propagating and broaden service coverage. Aimed at the development, more attention must be paid to home care service. Community home care isn't only to solve problems of poor men, but also a full range of services for the elderly. Old men in better economic conditions, can choose some services delivered by private market.

Specialize and improve the quality of service. Standardize purchase system of government purchase. At the meanwhile, strictly normalize the confirmation procedure of home care, and pay more attention to fairness in the bidding. In order to fully improve the quality of home care service, supervising and examining to service must be enhanced.

Establish an evaluation mechanism. Objective and fair evaluation is an important approach to promote services for the aged. Some supervisors could be set in the community, visiting service objects regularly. In addition, we can learn from international advanced experience. Give full play to social forces, bring in the third-party organization, and make evaluator professional.

Establish a stable home care service team. In order to ensure the quality of service, service staves should be trained about the knowledge and skills of aged mind and care, employment with certificates. According to the level of skill examination, staves engage in the corresponding level of service. Implement professional qualification certification system, so that service level and quality can be improved constantly.

Improve ability of service in community health station. Government should invest more funds 
and strengthen policy support for community health service station, creating favorable medical environment. Community health service station ought to meet the need of the elderly and provide prevention, health care, medical service, health guidance, etc. Attract more old people to go to a doctor in the community.

\section{References}

[1] $\mathrm{Xu}$ Yongxiang, Community development in China, East China University of Science and Technology Press, Shanghai, 2002, 33-34.

[2] Zhu Yong, Community service development research report in Guangzhou, quoted from report on social welfare and social progress in China, Social Science Academic Press, Beijing, 1996, 274.

[3] Ju Qiujing, Deng Weihua, Simple analysis on home care service [J], The Economy of Liaoning Province, 2004, 12.

[4]Shi Meihua, Study on the household supporting service for the aged in view of social stratification, Master Degree Thesis Changchun University of Technology, 2011, 4.

[5]Su Chang, Three questions should be paid attention in the home and institution care service, 2007.

[6]Su Chang, Study on city endowment patterns in Tianjin [D], Master Degree Thesis Tianjin University, 2007.

[7]Yan Qingchun, The advantages and disadvantages of four home care service modes [J] Social Welfare, 2009, 3.

[8]Liu Jing, Exploration on life quality evaluation index to the aged who can't provide for oneself in home care [J], Journal of Population, 2005(1).

[9]Zeng Zhi, Comparison domestic home care patters [D], Master Degree Thesis Wuhan University of Technology, 2008.

[10]Guo Jingcheng, Comparison and reference to international home care patters [J], 2010, 1.

[11] A. Jamieson, Home care for older people in Europe: a comparison of policies and practices, Oxford, Oxford University Press, 1991,128.

[12] Susan. Tester, Cross national comparisons of community care for the elderly, 2002(4), 9.

[13]J. Myles, Why we need a new welfare state: Oxford University Press, New York, 1-25.

[14]Xiu Hongfang, Research on community service support home care service, Doctoral Dissertation Nankai University, 2013, 5. 